\title{
A proteção do patrimônio cultural mineiro pela regulamentação da produção e comercialização dos queijos artesanais
}

\author{
The protection of the mining cultural heritage by regulating the production \\ and commercialization of handcraft cheese
}

Stela Gomes Ferreira Mestranda em Direito Ambiental na Escola Superior Dom Helder Câmara. Bolsista FAPEMIG stelagferreira@gmail.com

Beatriz Souza Costa

Doutora e Mestre em Direito Constitucional pela Universidade Federal de Minas Gerais (UFMG). Professora da disciplina de Direito Constitucional Ambiental, do Programa de Pós-Graduação da Escola Superior Dom Helder Câmara. biaambiental@yahoo.com.br

Resumo: Este trabalho tem como objetivo analisar a importância do patrimônio cultural como forma de preservação da identidade de uma coletividade, tendo como recorte a produção artesanal de queijo no estado de Minas Gerais. Neste contexto, é pertinente questionar se o reconhecimento formal deste patrimônio ensejou mudanças legislativas que preservam e ampliam a possibilidade de produção tradicional do alimento. Como hipótese se levanta que o aspecto cultural, apesar de ser um importante marco para fundamentar as evoluções das normativas, não é o único elemento decisivo, diante da existência de interesses econômicos. Para isto, utiliza-se da metodologia jurídica-teórica, bem como o raciocínio dedutivo e pesquisas bibliográficas transdisciplinares abordando reflexões que perpassam pelo Direito Ambiental e Constitucional, com interface na antropologia, além da análise no campo legislativo.

Palavras-chaves: meio ambiente cultural; patrimônio cultural; patrimônio imaterial; queijo artesanal.

Abstract: This work aims to analyze the importance of cultural heritage as a way of preserving the identity of a community, with a focus on artisanal cheese production in the state of Minas Gerais. In this context, it is pertinent to question whether the formal recognition of this heritage led to legislative changes that preserve and expand the possibility of traditional food production. As a hypothesis, it arises that the cultural aspect, despite being an important landmark to support the evolution of regulations, is not the only decisive element, given the existence of economic interests. For this, it uses the legal-theoretical methodology, as well as deductive reasoning and transdisciplinary bibliographic research addressing reflections that pervade Environmental and 
Constitutional Law, with an interface in anthropology, in addition to analysis in the legislative field.

Keywords: cultural heritage; cultural environment; intangible heritage; handcraft cheese.

\section{Para citar este artigo}

ABNT NBR 6023:2018

FERREIRA, Stela Gomes; COSTA, Beatriz Souza. A proteção do patrimônio cultural mineiro pela regulamentação da produção e comercialização dos queijos artesanais. Prisma Jurídico, São Paulo, v. 20, n. 2, p. 296-310, jul./dez. 2021. http://doi.org/10.5585/prismaj.v20n2.19342.

\section{Introdução}

A cultura, conforme aponta Geertz (2008), é elemento da construção da identidade do ser humano, desta forma não se limita a elementos físicos e materiais. Os sentidos da própria existência são extraídos de várias fontes e merecem ser reconhecidos como patrimônio cultural. Assim, os conhecimentos e práticas tradicionais se tornam uma fonte de compreensão da conjuntura da realidade, ligando o presente e passado, que refletem nas formas de viver, na subsistência de uma comunidade e na perpetuação de seus valores.

Diante da importância dessa construção identitária, a norma constitucional reconhece e protege o patrimônio cultural imaterial brasileiro. Apesar desse reconhecimento, em alguns casos, a concretização da liberdade acerca da continuidade do uso destes conhecimentos tradicionais enfrenta óbices técnicas. Este é o caso do modo tradicional de produção e comercialização de Queijo Minas Artesanal (QMA) no estado de Minas Gerais

À vista disso, é pertinente questionar quais foram as influências dos instrumentos legais acerca da produção e comercialização do QMA na perpetuação da tradição cultural mineira. Neste diapasão, parte-se da premissa de que tais regulações obstaram as técnicas tradicionais, colocando o produto na clandestinidade, prejudicando em maior monta os pequenos produtores.

Assim, primeiro se buscará caracterizar como o patrimônio cultural é tratado no ordenamento jurídico brasileiro. Em seguida, a atenção se dirigirá para demonstrar como que o queijo repercute como objeto imaterial na cultura mineira e brasileira. Por fim, serão indicadas as legislações e regulamentações técnicas que exerceram mudanças na atividade produtiva do alimento ao longo dos anos desaguando no recente decreto estadual de Minas Gerais que reconhece a vulnerabilidade do particular-produtor perante o Estado. 
Para tanto, será feita uma abordagem qualitativa com pesquisas exploratórias teóricasjurídicas e legislativas por meio do procedimento dedutivo. A pesquisa bibliográfica como técnica utilizada se apoiará nos ensinamentos de Miranda (2006) acerca da tutela do patrimônio cultural brasileiro e da compreensão da cultura proposta por Geertz (2006) como sistema de símbolo significantes.

\section{Patrimônio cultural}

A compreensão do patrimônio cultural parte-se da definição de cultura. Para Geertz (2008) cultura não seria um poder, nem mesmo uma construção casuística, mas sim um contexto do qual os acontecimentos sociais, comportamentos e instituições podem ser descritos de forma inteligível. Desta forma, a cultura abrange os elementos que identificam o sujeito com sua essência, sendo a resposta da busca por entendimento em si próprio (COSTA, 2010).

Diante da intrínseca relação da construção do ser com a cultura, observa-se que a salvaguarda dos bens culturais está presente na história. Miranda (2006) aponta que a primeira preocupação governamental brasileira quanto ao patrimônio cultural ocorreu no ano de 1742 , quando o Vice-Rei do Brasil ordenou a paralisação das obras de transformação do Palácio das Duas Torres, construído por Maurício de Nassau.

Enquanto isso, no plano legislativo, o primeiro diploma federal foi o Decreto 22.928/33 que reconheceu a cidade de Ouro Preto como monumento nacional. Neste caminhar, no ano de 1937, o Decreto 25 estabeleceu o tombamento ${ }^{1}$, que é um dos principais instrumentos de proteção ao bem cultural. Outros marcos que merecem destaque são as legislações que proibiam a saída de obras produzidas no Brasil ${ }^{2}$.

Sob a égide da Constituição Federal de 1988, o meio ambiente é consagrado como um direito fundamental, que possuí influência direta na sadia qualidade de vida ${ }^{3}$. Ademais, a compreensão de que o meio ambiente possuí caráter difuso e intergeracional evidencia a relação insociável, interdependente e transversal com a existência do ser-humano (KALIL; FERREIRA, 2017; CALDAS; SILVA; BARROSO, 2020).

\footnotetext{
${ }^{1}$ O Decreto 25/37 foi recepcionado pela Constituição Federal de 1988. Com a vigência do Código de Processo Civil no ano de 2015, foi revogado seu art. 22, que versava sobre o direito de preferência dos entes federativos. ${ }^{2}$ A Lei 4.845/65 proíbe a saída, para o exterior, de obras de arte e ofícios produzidos no país, até o fim do período monárquico. A Lei 5.471/68 dispõe sobre a exportação de livros antigos e conjuntos bibliográficos brasileiros.

3 Art. 225. Todos têm direito ao meio ambiente ecologicamente equilibrado, bem de uso comum do povo e essencial à sadia qualidade de vida, impondo-se ao poder público e à coletividade o dever de defendê-lo e preservá-lo para as presentes e futuras gerações.
} 
Nessa conjuntura, o patrimônio cultural é compreendido como aspecto do meio ambiente, sendo uma de suas espécies ${ }^{4}$, Logo, o meio ambiente cultural conforme disposto no art. 216 da CF/88 é constituído por "bens de natureza material e imaterial, tomados individualmente ou em conjunto, portadores de referência à identidade, à ação, à memória dos diferentes grupos formadores da sociedade brasileira" (BRASIL, 1988).

Frisa-se, que os incisos que se seguem ${ }^{5}$, apesar de elencarem os objetos constitutivos do patrimônio cultural, não possuem rol taxativo. Há um caráter dinâmico na cultura, devido a própria construção do indivíduo, que não é um projeto pronto. Assim, acertada a construção legislativa que permite comportar as transformações das referências de bem cultural.

O interesse da preservação do patrimônio cultural abrange todos os entes federativos. Desta feita, a tratativa do assunto pode ser comum, conforme aponta o inciso III do art. $23^{6}$ da Constituição Federal. No âmbito legislativo, concorrem a União, Estados e ao Distrito Federal, nos moldes dos incisos VII e VIII do art. 24 da CF/88 ${ }^{7}$. Contudo, ainda resta possibilidade de legislação proposta pelo município, desde que sua abrangência seja local e de forma suplementar aos dispositivos federais e estaduais, conforme incisos I e II do art. 30 da CF/88 ${ }^{8}$.

O reconhecimento constitucional proporciona característica dúbia ao patrimônio cultural, visto que se torna um direito-dever. Neste sentido, o Estado deve garantir a todos o pleno exercício dos direitos culturais e o acesso às fontes de cultura ${ }^{9}$, que de forma compartilhada com a sociedade ${ }^{10}$, promoverá a custódia do patrimônio cultural.

\footnotetext{
${ }^{4}$ Miranda (2006) assevera que a divisão do meio ambiente em aspectos compositivos tem o objetivo de facilitar a identificação do bem imediatamente agredido, dessa forma elenca o meio ambiente natural, do trabalho, artificial e cultural.

${ }^{5}$ Art. 216, CF/88:

I - as formas de expressão;

II - os modos de criar, fazer e viver;

III - as criações científicas, artísticas e tecnológicas;

IV - as obras, objetos, documentos, edificações e demais espaços destinados às manifestações artístico-culturais;

V - Os conjuntos urbanos e sítios de valor histórico, paisagístico, artístico, arqueológico, paleontológico, ecológico e científico.

${ }^{6}$ Art. 23. É competência comum da União, dos Estados, do Distrito Federal e dos Municípios:

III - proteger os documentos, as obras e outros bens de valor histórico, artístico e cultural, os monumentos, as paisagens naturais notáveis e os sítios arqueológicos;

${ }^{7}$ Art. 24. Compete à União, aos Estados e ao Distrito Federal legislar concorrentemente sobre:

VII - proteção ao patrimônio histórico, cultural, artístico, turístico e paisagístico;

VIII - responsabilidade por dano ao meio ambiente, ao consumidor, a bens e direitos de valor artístico, estético, histórico, turístico e paisagístico;

8 Art. 30. Compete aos Municípios:

I - legislar sobre assuntos de interesse local;

II - suplementar a legislação federal e a estadual no que couber;

9 Art. 215. O Estado garantirá a todos o pleno exercício dos direitos culturais e acesso às fontes da cultura nacional, e apoiará e incentivará a valorização e a difusão das manifestações culturais.

${ }^{10}$ Art. 216, § $1^{\circ}$. O Poder Público, com a colaboração da comunidade, promoverá e protegerá o patrimônio cultural brasileiro, por meio de inventários, registros, vigilância, tombamento e desapropriação, e de outras formas de acautelamento e preservação.
} 
Em razão disso, a abordagem do bem cultural deve ser realizada ante a perspectiva de Direito Fundamental, tal como o meio ambiente haja vista ser um de seus elementos. Nesse sentido, o patrimônio cultural é classificado como um direito fundamental de terceira dimensão, que está atinente a solidariedade e atinge interesses difusos. É importante frisar que as dimensões dos direitos fundamentais, embora elencados em distintas dimensões, devem ser compreendidos de forma integrada, inexistindo entre eles hierarquia. (COSTA, 2010; SARLET; MARINONI; MITIDIERO, 2018)

Outro ponto atinente que reforça essa qualificação se dá pela proteção do bem pelo Direito Penal, diante da característica fragmentária e subsidiária do ramo, nota-se que a tratativa da matéria ressalta a importância do bem jurídico. Assim, a Lei 9.605/98 dispõe em seu capítulo V, seção VI, as ações que constituem crime contra o ordenamento urbano e o patrimônio cultural.

Retomando a noção de dinamicidade da definição de bem ambiental, o Art. $65^{11}$ da referida lei de crimes ambientais é exemplo prático. Sua redação foi alterada pela Lei $n^{\circ}$ $12.408 / 11^{12}$, que retirou do tipo penal o ato de grafitar edificação ou monumento urbano. Essa mudança legislativa decorre do reconhecimento do grafite como arte e manifestação cultural.

No que toca a imaterialidade do bem cultural, necessária a ressalva quanto seu conhecimento e salvaguarda, visto ser recente na política de preservação patrimonial. Este se constitui por um suporte físico indireto, que não possui por si só significado, mas constitui a representação de costumes, tradições e saberes (SILVA; SILVA, 2020; IPHAN, 2020). Dessa forma, a visão constitucional firmou:

[...] o entendimento que patrimônio cultural imaterial, diversidade cultural e identidade são indissociáveis, reconhecendo que as transformações ocorridas nas formas as de interação entre as comunidades e o seu meio sociocultural interferem nos seus modos de vida e na sua história (SILVA; SILVA, 2020, p. 44)

Ademais, o Decreto $\mathrm{n}^{\mathrm{o}} 3.551$ de 4 de agosto de 2001 "institui o Registro de Bens Culturais de Natureza Imaterial que constituem o patrimônio cultural brasileiro, cria o Programa Nacional do Patrimônio Imaterial e dá outras providências”, que por sua vez estipula o Registro de Bens Culturais de Natureza Imaterial que constituem patrimônio cultural brasileiro. Assim, há o objetivo identificar e produzir conhecimento sobre o bem imaterial documentado servindo como instrumento legal de preservação que permite:

\footnotetext{
${ }^{11}$ Art. 65. Pichar ou por outro meio conspurcar edificação ou monumento urbano: Pena - detenção, de 3 (três) meses a 1 (um) ano, e multa.

${ }^{12}$ Altera o art. 65 da Lei ${ }^{\circ}$ 9.605, de 12 de fevereiro de 1998, para descriminalizar o ato de grafitar, e dispõe sobre a proibição de comercialização de tintas em embalagens do tipo aerossol a menores de 18 (dezoito) anos.
} 
[...] o desenvolvimento de programas e ações governamentais e pode ser usado para estimular mobilizações reivindicatórias em prol da implantação de ações preservacionistas, capazes de garantir a profusão de manifestações culturais e criar condições para sua sustentabilidade, ou ainda servir para suscitar a consciência da preservação do bem por parte de agentes sociais (SILVA; SILVA, 2020, p. 46)

Ainda assim, existem ressalvas quanto à definição da imaterialidade de um bem cultural. Meneses (2009) justifica que a dicotomia entre o material e imaterial reflete no embate do natural e cultural e que tal separação não é possível para o entendimento dos modos de fazer tradicionais, visto que as técnicas, os produtos e seus significados formam uma unidade complexa.

Apesar desses apontamentos, que propiciam relevantes reflexões ante ao próprio caráter simbólico e dinâmico da cultura, se toma a imaterialidade do bem cultural como característica que o distingue do material. Por isso, são necessários instrumentos de proteção diferenciada, que devem possibilitar a perpetuação de saberes com incentivo às práticas tradicionais, que abarcam maior complexidade do que a preservação estrutural de uma obra física.

\section{A trajetória do queijo em Minas Gerais}

A alimentação, muito mais que uma forma de satisfazer necessidades fisiológicas, representa significados culturais e sociais por toda história do ser humano. O cultivo, o preparo, os ingredientes e a forma de se comer são elementos que circundam religiões, identidades, vínculos sociais e o manejo com o meio ambiente.

O reconhecimento da culinária mineira é extenso e o queijo é um dos produtos que faz parte dessa construção identitária. Tamanha importância não é limitada ao estado, mas reflete nacionalmente. Por isto, o Instituto do Patrimônio Histórico e Artístico Nacional (IPHAN), no dia 15 de maio de 2008, reconheceu o modo artesanal de fazer queijo-de-minas como patrimônio imaterial brasileiro, tendo em vista que:

\footnotetext{
O registro do Queijo Minas Artesanal de Minas Gerais representa, sem dúvida, marco importante para [...] a garantia da sustentabilidade desse produto tão emblemático da identidade mineira como o são as montanhas, a habilidade política e o espírito libertário. Em torno do Queijo Artesanal de Minas Gerais se desenvolveram hábitos, costumes, manifestações culturais e relações socioeconômicas. E uma insuperável arte do "saber fazer" do homem simples do interior, umas das melhores expressões da alma mineira. Por mais que se avance na modernidade e que se aprimorem a tecnologia e os equipamentos, o modo artesanal de fazer o queijo será sempre uma forte referência da melhor tradição mineira. (IPHAN, 2008, p. 6).
}

A receita digna de tanto reconhecimento tem como origem técnicas portuguesas, que chegaram ao território brasileiro durante o ciclo de ouro. Em Minas Gerais a produção foi 
tomando contorno próprio, tendo como característica a utilização do leite-cru ordenhado nas propriedades rurais familiares, que é submetido à maturação e do uso de utensílios de madeira. As pastagens típicas, o clima propenso para o desenvolvimento das bactérias do processo se soma aos aspectos sociais e culturais que perpetuam a forma tradicional de produção com "modo de fazer próprio na manipulação do leite, dos coalhos, das massas, das formas de prensagem, da cura", que se estendem até a forma de comercialização (IPHAN, 2006, 2014; CASTRO, 2019). Ademais:

\begin{abstract}
O processamento de Queijo Minas Artesanal tem uma peculiaridade que abre oportunidades para as unidades de pequena escala e especialmente para o segmento de estabelecimentos rurais da agricultura familiar. Como o processamento é realizado imediatamente após a ordenha e o leite não sofre tratamento térmico, não existe necessidade de investimentos em caldeiras, pasteurizadores e nem nas estruturas para estabelecer a cadeia do frio no sistema de produção. Com isso, diminuem-se os custos de implantação das queijarias. (MONTEIRO, 2018, p. 13).
\end{abstract}

Para além da importância cultural, a produção tradicional do queijo minas artesanal produz efeitos econômicos, o vínculo do alimento perpassa a identidade mineira e se institui como fomentador da economia local, que permeia a sustentação econômica de várias famílias. Conforme o IPHAN (2014), cerca de 30 mil famílias estavam empenhadas na produção de queijos e produtos derivados de leite, gerando empregos diretos e indiretos.

Apesar de toda importância cultural e econômica, a atividade de produção e comercialização do queijo artesanal mineiro sempre foi permeada por embates técnicos e legislativos. A técnica tradicional, que se distancia das práticas industriais, muitas vezes não se adaptou às exigências sanitárias e registrais. Logo, a perpetuação desse saber sustentáculo da história mineira e da economia de muitos produtores ficou prejudicada e fadada à clandestinidade, haja vista que diversas legislações não permitiam o comércio do alimento produzido da maneira tradicional.

\title{
4 As legislações envolvidas no modo de fabricação do queijo artesanal
}

A linha histórica das legislações acerca da fabricação do queijo artesanal mineiro é longa. Além das regulamentações da federação e do estado de Minas Gerais, portarias, regulamentos e instruções normativas de órgãos administrativos definiram o rumo da produção e comércio do alimento. Para que fosse possível apresentar esse arcabouço foram utilizados os apontamentos de Castro (2019), Monteiro, Chaves (2018) e IPHAN (2014). 
O Ministério da Agricultura, Pecuária e Abastecimento (MAPA), por meio da resolução No 7 no ano $2000^{13}$, estabeleceu que o Serviço de Inspeção Federal (SIF) seria o responsável por regularizar a produção e comercialização de queijos artesanais. Para isso, seria necessário o tratamento térmico do leite e maturação de no mínimo 21 dias, havendo a exceção para o comércio de leite cru somente com a maturação de 60 dias. Tais requisitos burocratizam a comercialização e limitavam o processo tradicional devido ao período de maturação e limitações ao uso do leite cru, visto serem incompatíveis com o processamento dos queijos tradicionais (MONTEIRO; CHAVES, 2018).

Em resposta, no ano de 2002, o governo do estado de Minas Gerais, por meio da Secretaria de Agricultura, Pecuária e Abastecimento com a EMATER-MG realizaram o "Programa de Melhoria na Qualidade do Queijo Minas Artesanal”, como forma de apoio aos produtores para regulamentação de sua produção. Nesta conjuntura, a Lei $n^{\circ}$ 14.185/2002 reconheceu o processo do queijo e permitiu a produção do queijo artesanal, feito por meio do leite cru, dentro dos limites do estado ${ }^{14}$. Contudo, persistiam os prejuízos no tocante ao comércio interestadual.

Somente em 2011, por meio da Instrução Normativa No 57 do MAPA ${ }^{15}$, foi possível a produção de queijo com o uso do leite cru com menos de 60 dias de maturação. Contudo, era

${ }^{13}$ Resolução No 7 do Mapa (Brasil, 2000):

CRITÉRIOS DE FUNCIONAMENTO E DE CONTROLE DA PRODUÇÃO DE QUEIJARIAS, PARA SEU RELACIONAMENTO JUNTO AO SERVIÇO DE INSPEÇÃO FEDERAL:

$(\ldots)$

5.2. O queijo Minas deve ser produzido a partir de leite tratado termicamente, quando tiver período de maturação inferior a 60 (sessenta) dias, apresentando, para isso, tal resultado negativo para a prova de fosfatase alcalina residual para o leite e/ou queijo, de acordo com metodologia analítica oficial do Ministério da Agricultura e do Abastecimento.

5.4. Excepcionalmente, o queijo Minas pode ser produzido a partir de leite cru; nestas condições, o mesmo só poderá ser comercializado para o consumo após 60 (sessenta) dias de cura ou maturação em entreposto de laticínios registrado no SIF, de acordo com os termos da Portaria 146/96-MA, de 07 de março de 1996, a contar da data da sua chegada neste estabelecimento (...)

14 "Para tal, foi criada uma estrutura sob supervisão do IMA visando cadastrar as queijarias artesanais e certificar a qualidade dos produtos, responsabilizando os seus proprietários. Com isso, foram estabelecidas regras detalhadas sobre a produção e comercialização dos queijos artesanais. Foram editadas as normas para a defesa sanitária dos rebanhos fornecedores de leite, os requisitos básicos de instalações, materiais, equipamentos e rotulagem. Também houve preocupação com a preservação dos modos de fazer tradicionais dos diferentes queijos." (MONTEIRO; CHAVES, 2018, p. 20)

${ }^{15}$ Art. $1^{\text {o}}$ : Permitir que os queijos artesanais tradicionalmente elaborados a partir de leite cru sejam maturados por um período inferior a 60 (sessenta) dias, quando estudos técnico-científicos comprovarem que a redução do período de maturação não compromete a qualidade e a inocuidade do produto.

$\S 1^{\circ}$ A definição de novo período de maturação dos queijos artesanais será realizada por ato normativo específico, após a avaliação dos estudos por comitê técnico-científico designado pelo Ministério da Agricultura, Pecuária e Abastecimento.

Art. $2^{\circ}$ A produção de queijos elaborados a partir de leite cru, com período de maturação inferior a 60 (sessenta) dias, fica restrita a queijaria situada em região de indicação geográfica certificada ou tradicionalmente reconhecida e em propriedade certificada oficialmente como livre de tuberculose e brucelose, sem prejuízo das demais obrigações dispostas em legislação específica. 
necessário que a qualidade e a inocuidade do produto fossem comprovadas por meio de estudo técnico, devido à redução no período de maturação ${ }^{16}$, ademais somente as regiões geograficamente certificadas se valeriam dessa abertura (BRASIL, 2011).

Até 2018 várias alterações acerca da produção e comercialização do queijo ocorreram. No âmbito estadual, a Lei. 19.476/11 regulamentada pelo Decreto 45.821/11 estabeleceu regras para qualificação e controle de qualidade de produtos para pequenas empresas agrícolas, com a compulsória habilitação junto ao Instituto Mineiro de Agropecuária (IMA) para obtenção de registro como produto inspecionado; Nos órgãos administrativos a Portaria N $^{\circ} 1.252 / 2012$ do IMA definiu normas técnicas para pequenas empresas rurais para produção de produtos de origem animal; O MAPA por meio da Instrução Normativa $\mathrm{N}^{\circ} 16$ de 23 de junho de 2015, estabeleceu normas específicas de inspeção e fiscalização sanitária de produtos de origem animal para o território nacional. Contudo, o ato complementar que dispõe o art. $15^{17}$ não fora publicado, por conseguinte a comercialização interestadual do QMA se restringiu ao registro/título de relacionamento do produto; no âmbito Federal, o Decreto 9.013/17 estabeleceu regras complementares para as pequenas empresas agroindustriais (CASTRO, 2019).

O excesso da legislação, que deixava o produto artesanal na clandestinidade, possibilitou situações curiosas. Em 2017, após ação da vigilância sanitária em um estande alimentício que comercializava produtos em um festival de música, foram apreendidos cerca de 160 quilos de produtos artesanais que não continham selo de inspeção fiscal (TEIXEIRA, 2017). O concurso Mondial du Fromage et des Produits Laitiers, realizado em 2019, rendeu 50 medalhas para os produtores de queijo de Minas Gerais, que embarcaram sem a autorização das autoridades brasileiras (MELO; RODRIGUES; SOARES, 2019).

Em 2018, ressalta-se o Programa de Certificação de Produtos Agropecuários e Agroindustriais (Certifica Minas), por meio da Lei estadual $\mathrm{N}^{\circ} 22.920$, que versou sobre a habilitação sanitária de estabelecimentos agroindustriais de pequeno porte ${ }^{18}$. Ademais, houve

\footnotetext{
${ }^{16}$ Após dois anos, com a superveniência da Instrução Normativa $N^{o}$ 30, a competência para atestar menor período de maturação foi conferida aos estados e municípios.

17 Art. 15. A Secretaria de Defesa Agropecuária do MAPA publicará em 180 (cento e oitenta) dias após a publicação desta Instrução Normativa, em ato complementar, o detalhamento das normas para as diversas cadeias produtivas, dos procedimentos e demais normas necessárias para a instalação e registro de inspeção sanitária para a agroindústria de pequeno porte, produtos e rotulagem, considerando a especificidade da agroindústria de pequeno porte.

Parágrafo único. O Ato complementar referente ao processamento de leite ou seus derivados dos estabelecimentos agroindustriais de pequeno porte será publicado em 60 (sessenta) dias.

18 "De acordo com a nova legislação, a habilitação se inicia pelo cadastro provisório do estabelecimento no IMA, com a formulação de um termo de compromisso, com prazo máximo de dois anos, para a adequação das práticas e das instalações do estabelecimento agroindustrial de pequeno porte às normas. A Certificação é da propriedade e abrange as áreas: georreferenciamento, rastreabilidade, Responsabilidade Ambiental, Responsabilidade Social,
} 
alteração na comercialização interestadual dos produtos artesanais por meio da instituição do Selo-Arte, por meio da Lei Federal n ${ }^{\circ}$ 13.680/2018, compreendeu um viés orientador a inspeção e fiscalização dos produtos artesanais ${ }^{19}$.

Nesse panorama, a Lei estadual no $23.157 / 18$ entrou em vigor, estabelecendo que:

\begin{abstract}
Art. $3^{\circ} \mathrm{O}$ queijo é um dos símbolos da identidade mineira e sua produção artesanal deve ser reconhecida e protegida pela administração pública estadual.

Parágrafo único. A produção artesanal do queijo é forma de agregação de valor à produção leiteira que pode orientar-se pela cultura regional, pelo emprego de técnicas tradicionais ou por inovações técnicas que garantam ao produto a aparência e o sabor específicos do tipo de queijo artesanal.
\end{abstract}

Nessa ordem de ideias, no ano de 2019 o Governo Federal, por meio da Lei Federal n ${ }^{\circ}$ 13.860, o queijo artesanal foi compreendido como "aquele elaborado por métodos tradicionais, com vinculação e valorização territorial, regional ou cultural, conforme protocolo de elaboração específico estabelecido para cada tipo e variedade, e com emprego de boas práticas agropecuárias e de fabricação", com a permissão de sua venda em todo território nacional (BRASIL, 2019). Em decorrência, o Decreto 9.918/19 regulamentou o Selo Arte, dessa forma os Estados serão responsáveis para a concessão do selo e posterior fiscalização desses produtos.

Por fim, o Decreto estadual n 48.024, de 19 de agosto de 2020 regulamenta a Lei N $^{\circ}$ 23.157/2018. A previsão normativa tem como bojo norteador a precaução e prevenção da saúde e a vulnerabilidade do particular-produtor perante o Estado (Art. $2^{\circ}$, I, III). Suas disposições abrem margem para o reconhecimento de outros modos de fazer do queijo artesanal, como patrimônio cultural, por meio de solicitação de organizações representativas dos produtores (Art. $5^{\circ}, \S \S 1^{\circ}$ e $2^{\circ}$ ) e admite variedades derivadas (Art. $7^{\circ}$, parágrafo único).

Destarte, as várias legislações acerca da produção e comercialização do queijo minas tradicional produziram efeitos na perpetuação de seu legado histórico e cultural, visto que a regulamentação esbarra em questões sanitárias com reflexos na saúde do consumidor.

Assim, é necessário trilhar um caminho que permita o encorajamento na continuidade da atividade, devido a sua importância na construção do próprio ser, e que ao mesmo tempo não se olvide da segurança alimentar. Esses embates revelam o "quanto é importante que o meio acadêmico esteja em forte interação com os legisladores e com os órgãos de fomento,

\footnotetext{
Gerenciamento da Propriedade e as Normas para produção do QMA, deste a ordenha até a comercialização. Estas normas abrangem cinco requisitos: cumprimento das boas práticas de fabricação; realização de análises da água e do queijo, de acordo com os parâmetros da legislação vigente; sanidade do rebanho e saúde dos trabalhadores. (...) Durante a vigência do termo de compromisso, os produtores ficam autorizados a comercializar os produtos do estabelecimento cadastrado". (CASTRO, 2019, p. 21)

${ }^{19}$ Art. 10-A, $4^{\text {o }}$ : A inspeção e a fiscalização da elaboração dos produtos artesanais com o selo ARTE deverão ter natureza prioritariamente orientadora.
} 
assistência técnica e extensão rural para respaldar a elaboração de normas e a sua implementação" (MONTEIRO; CHAVES, 2018, p.15).

\section{Considerações finais}

Diante da importância constitucional prevista ao patrimônio cultural, como um dos elementos do meio ambiente, sua defesa como um compromisso de todos, sociedade e poder público, reflete na sadia qualidade de vida. Este tratamento não se limita aos bens materiais, abarcando os de natureza imaterial, que refletem nas formas de expressão e os modos de criar, fazer e viver de um povo. Assim, os bens culturais são aqueles que permitem dar sentido a própria compreensão do indivíduo.

Nessa perspectiva, as características distintas de manejo, cultivo e produção de alimentos são circuncidados por conhecimentos tradicionais que espelham a construção identitária de uma sociedade. Em Minas Gerais, o queijo é símbolo da cultura mineira e a importância da forma tradicional da produção do alimento extravasa os limites do estado e é nacionalmente reconhecida formalmente por meio do IPHAN. Além da subsistência das características culturais e históricas de uma comunidade o produto é recurso econômico de várias famílias.

A técnica tradicional de produção do alimento foi permeada por diversas proposições legislativas, que embargavam a atividade, principalmente para os agricultores familiares com pequena escala de produção. O Poder-Público a fim de resguardar a saúde do consumidor obstou técnicas tradicionais como o uso do leite cru e tempo de maturação, prejudicando o comércio interestadual do alimento o colocando na clandestinidade. Entretanto, após um descaminho de normativas independentes, observa-se um panorama integrativo nas searas federais e estaduais quanto a regulamentação dessa fabricação.

O Decreto estadual $n^{\circ} 48.024 / 2020$ veio para regulamentar a Lei $n^{\circ} 23.157 / 18$ que já continha avanços significativos para a perpetuação da produção tradicional, em consonância da Lei Federal 13.860/19 e do Decreto Federal 9.918/19. Por meio dessa nova legislação, abre-se espaço para o reconhecimento de outras variedades de queijos produzidos em Minas Gerais, utilização de diferentes matérias-primas e de forma precursora, reconhece a vulnerabilidade do produtor ante o Estado como princípio norteador. Nesse viés, percebe-se que a evolução das normativas acerca da produção artesanal tem como arcabouço o seu reconhecimento como patrimônio cultural, que é completado pela compreensão da importância da atividade no aspecto econômico. 
Diante da regulamentação de uma atividade que tem incidência tão direta em valores constitucionais, como a proteção do patrimônio cultural e da ordem econômica, o poder público não deve agir somente como um sancionador, mas sim como agente que possibilite a necessária instrumentalização e capacitação dos produtores com fim de se atingir a harmonia entre as posturas sanitárias, continuidade dos saberes tradicionais e o proveito econômico.

\section{REFERÊNCIAS}

BRASIL. Constituição (1988). Constituição da República Federativa do Brasil. Disponível em: http://www.planalto.gov.br/ccivil_03/constituicao/constituicaocompilado.htm. Acesso em: 15 dez. 2021.

BRASIL. Decreto 3.551, de 4 de agosto de 2000. Institui o Registro de Bens Culturais de Natureza Imaterial que constituem patrimônio cultural brasileiro, cria o Programa Nacional do Patrimônio Imaterial e dá outras providências. Disponível em: http://www.planalto.gov.br/ccivil_03/decreto/d3551.htm. Acesso em 03 out. 2020.

BRASIL. Decreto no 22.928, de 12 de julho de 1933. Erige a cidade de Ouro Preto em monumento nacional. Disponível em: https://www2.camara.leg.br/legin/fed/decret/19301939/decreto-22928-12-julho-1933-558869-publicacaooriginal-80541-pe.html. Acesso em: 03 out. 2020.

BRASIL. Decreto no 25 de 30 de novembro de 1937. Organiza a proteção do patrimônio histórico e artístico nacional. Disponível em: Acesso em: http://www.planalto.gov.br/ccivil_03/decreto-lei/de10025.htm . Acesso em: 03 out. 2020.

Brasil. Decreto no 9.918 de 18 de julho de 2019. Dispõe sobre o processo de físcalização de produtos alimentícios de origem animal produzidos de forma artesanal. Ministério da Agricultura, Pecuária e Abastecimento. Brasília. Disponível em: https://www.in.gov.br/web/dou/-/decreto-n-9918-de-18-de-julho-de-2019-198615217. Acesso em: 03 out. 2020.

BRASIL. Instrução Normativa do MAPA n. 57, de 15 de dezembro de 2011. Diário Oficial da União, Brasília, 2011. Disponível em: https://www.normasbrasil.com.br/norma/instrucaonormativa-57-2011_78290.html. Acesso em: 03 out. 2020.

BRASIL. Lei n. ${ }^{\circ}$ 12.408, de 25 de maio de 2011. Altera o art. 65 da Lei ${ }^{\circ} 9.605$, de 12 de fevereiro de 1998, para descriminalizar o ato de grafitar, e dispõe sobre a proibição de comercialização de tintas em embalagens do tipo aerossol a menores de 18 (dezoito) anos. Disponível em: http://www.planalto.gov.br/ccivil_03/_ato2011-2014/2011/lei/112408.htm. Acesso: 26 set. 2020.

BRASIL. Lei n. ${ }^{0}$ 13.860, de 08 de julho de 2019. Dispõe sobre a elaboração e a comercialização de queijos artesanais e dá outras providências. Disponível em: http://www.planalto.gov.br/ccivil_03/_Ato2019-2022/2019/Lei/L13860.htm. Acesso: 26 set. 2020. 
BRASIL. Lei $\mathbf{n}^{\mathbf{0}}$ 9.605, de 12 de fevereiro de 1998. Dispõe sobre as sanções penais e administrativas derivadas de condutas e atividades lesivas ao meio ambiente, e dá outras providências. Disponível em http://www.planalto.gov.br/ccivil_03/leis/L9605.htm. Acesso: 26 set. 2020.

BRASIL. Ministério da Agricultura. Instrução Normativa no. 30, de 7 de agosto de 2013. Diário Oficial da União: seção 1, Brasília, DF. ano 150, no. 152, p. 19, 8 ago. 2013. Disponível em: https://www.in.gov.br/materia//asset_publisher/Kujrw0TZC2Mb/content/id/30808894/do1-2013-08-08-instrucao-normativan-30-de-7-de-agosto-de-2013-30808890. Acesso em: 15 dez. 2021.

CALDAS, Roberto Correia S. G.; SILVA, Camila Barreto P.; BARROSO, Saulo. Furtado. A transversalidade horizontal sistêmico-integrativa da dimensão ambiental de desenvolvimento sustentável: uma conceituação em evolução. Veredas do Direito, Belo Horizonte, v. 17, n. 38, p. 41-68, maio/ago. 2020. Disponível em:

http://revista.domhelder.edu.br/index.php/veredas/article/view/1749. Acesso em: 15 dez. 2021.

CASTRO, Mariana Tôrres de. Aspectos legais e produtivos, inocuidade e qualidade microbiológica do queijo minas artesanal produzido em uma propriedade rural de Santa Vitória-MG. 2019. 1423 f. Dissertação (Mestrado) - Curso de Tecnologia de Alimentos, Instituto Federal de Educação, Ciência e Tecnologia Goiano, Rio Verde, 2019. Disponível em: https://repositorio.ifgoiano.edu.br/handle/prefix/657. Acesso em: 03 out. 2020.

COSTA, Beatriz Souza. A proteção do patrimônio cultural como um direito fundamental. In: RESENDE, Elcio Nacur; SJ UMBERTO, Paulo. Temas de direito ambiental e desenvolvimento sustentável. Belo Horizonte: O Lutador, 2010. p. 66-88.

GEERTZ. Clifford. A interpretação das culturas. Rio de Janeiro. LTC, 2008.

IPHAN. INSTITUTO DO PATRIMÔNIO HISTÓRICO E ARTÍSTICO NACIONAL. [2020]. Patrimônio Imaterial. Disponível em: http://portal.iphan.gov.br/pagina/detalhes/234. Acesso em: 03 out. 2020.

IPHAN. INSTITUTO DO PATRIMÔNIO HISTÓRICO E ARTÍSTICO NACIONAL. Angela Gutierrez. Conselheira do Conselho Consultivo do Iphan. Parecer do Conselho Consultivo. Belo Horizonte, 2008. Disponível em:

http://portal.iphan.gov.br/uploads/ckfinder/arquivos/Modo_fazer_queijo_minas_parecer_cons elho_consultivo.pdf. Acesso em: 03 out. 2020.

IPHAN. INSTITUTO DO PATRIMÔNIO HISTÓRICO E ARTÍSTICO NACIONAL. Ministério da Cultura. Queijo Artesanal de Minas patrimônio cultural do Brasil: dossiê interpretativo. Belo Horizonte, 2006. Disponível em:

http://portal.iphan.gov.br/uploads/ckfinder/arquivos/Dossie_modo_fazer_queijo_minas.pdf. Acesso em: 03 out. 2020.

IPHAN. INSTITUTO DO PATRIMÔNIO HISTÓRICO E ARTÍSTICO NACIONAL. Modo artesanal de fazer queijo de Minas: Serro, Serra da Canastra e Serra do Salitre (Alto Paranaíba). Brasília, 2014. Disponível em: 
http://portal.iphan.gov.br/uploads/publicacao/Dossie_Queijo_de_Minas_web.pdf. Acesso em: 03 out. 2020.

KALIL, Ana Paula Maciel Costa; FERREIRA, Heline Sivini. A Dimensão Socioambiental do Estado de Direito. Revista Veredas do Direito, Belo Horizonte, v. 14, n. 28, jan./abr. 2017. Disponível em: http://revista.domhelder.edu.br/index.php/veredas/article/view/1010. Acesso em: 15 dez. 2021.

MELO, Régis; RODRIGUES, Fernanda; SOARES, Lucas. Queijos de MG conquistam 50 medalhas em concurso mundial na França. 2019. G1. Disponível em:

https://g1.globo.com/mg/sul-de-minas/minas-dos-queijos/noticia/2019/06/04/queijos-de-mgconquistam-serie-de-premios-em-concurso-mundial-na-franca.ghtml. Acesso em: 03 out. 2020.

MENESES, José Newton Coelho. Modos de fazer e a materialidade da cultura "imaterial": o caso do queijo artesanal de Minas Gerais. Patrimônio e Memória (UNESP), v. 5, p. 27-41, 2009. Disponível em: https://pem.assis.unesp.br/index.php/pem/article/view/75/527. Acesso em: 06 out. 2020.

MINAS GERAIS. Decreto n. ${ }^{\circ}$ 45.821, de 20 de dezembro de 2011. Dispõe sobre a habilitação sanitária do agricultor familiar e do estabelecimento agroindustrial rural de pequeno porte e dá outras providências. Belo Horizonte. Disponível em:

https://www.legisweb.com.br/legislacao/?id=140253.htm. Acesso: 26 set. 2020.

MINAS GERAIS. Decreto $\mathbf{n}^{\mathbf{0}} \mathbf{4 8 . 0 2 4}$ de 19 de agosto de 2020. Regulamenta a Lei $\mathrm{n}^{\circ}$ 23.157, de 18 de dezembro de 2018, que dispõe sobre a produção e a comercialização dos queijos artesanais de Minas Gerais. Disponível em:

https://www.almg.gov.br/consulte/legislacao/completa/completa.html?tipo=DEC\&num=4802 4\&comp=\&ano=2020. Acesso: 26 set. 2020.

MINAS GERAIS. Lei n. ${ }^{\circ}$ 14185, de 31 de janeiro de 2002. Dispõe sobre O Processo de Produção do QMAe Dá Outras Providências. Belo Horizonte. Disponível em: https://www.legisweb.com.br/legislacao/?id=140253.htm. Acesso: 26 set. 2020.

MINAS GERAIS. Lei n. ${ }^{0}$ 19.476, de 11 de janeiro de 2011. Dispõe sobre a habilitação sanitária de estabelecimento agroindustrial de pequeno porte no Estado e dá outras providências. Disponível em: https://www.legisweb.com.br/legislacao/?id=142621. Acesso: 26 set. 2020.

MINAS GERAIS. Lei n. ${ }^{\circ}$ 23.157, de 18 de dezembro de 2018. Dispõe sobre A Produção e A Comercialização dos Queijos Artesanais de Minas Gerais. Belo Horizonte. Disponível em: https://www.almg.gov.br/consulte/legislacao/completa/completa.html?tipo=LEI\&num=23157 $\&$ comp=\&ano=2018. Acesso: 26 set. 2020.

MIRANDA, Marcos Paulo de Souza. Tutela do patrimônio cultural brasileiro-doutrinajurisprudência- legislação. Belo Horizonte: Del Rey, 2006.

MONTEIRO, Rodrigo Paranhos; CHAVES, Ana Carolina Sampaio Doria. O Queijo Minas Artesanal e seu potencial para agroindústria familiar. In: BRASIL. Rodrigo Paranhos Monteiro. Queijo Minas Artesanal: valorizando a agroindústria familiar. Brasília: Embrapa, 
2018. p. 17-34. Disponível em:

http://www.infoteca.cnptia.embrapa.br/infoteca/handle/doc/1110220. Acesso em: 29 set. 2020.

SARLET, Ingo Wolfgang; MARINONI, Luiz Guilherme; MITIDIERO, Daniel. Curso de direito constitucional. 7. ed. São Paulo: Saraiva, 2018.

SILVA, Paulo Sérgio; SILVA, Ana Paula da. Patrimônio Cultural Imaterial: a atuação do iphan e do iepha/mg. Cadernos de Pesquisa do Cdhis, [S.L.], v. 33, n. 1, p. 40-68, 24 jun. 2020. Semestral. EDUFU - Editora da Universidade Federal de Uberlândia. http://dx.doi.org/10.14393/cdhis.v33n1.2020.55181. Disponível em: http://www.seer.ufu.br/index.php/cdhis/article/view/55181/29392. Acesso em: 06 out. 2020.

TEIXEIRA, Patrícia. Após ação da Vigilância Sanitária, chef Roberta Sudbrack decide fechar estande no Rock in Rio. 2017. G1. Disponível em: https://g1.globo.com/musica/rockin-rio/2017/noticia/apos-acao-da-vigilancia-sanitaria-chef-roberta-sudbrack-decide-fecharestande-no-rock-in-rio.ghtml. Acesso em: 03 out. 2020. 